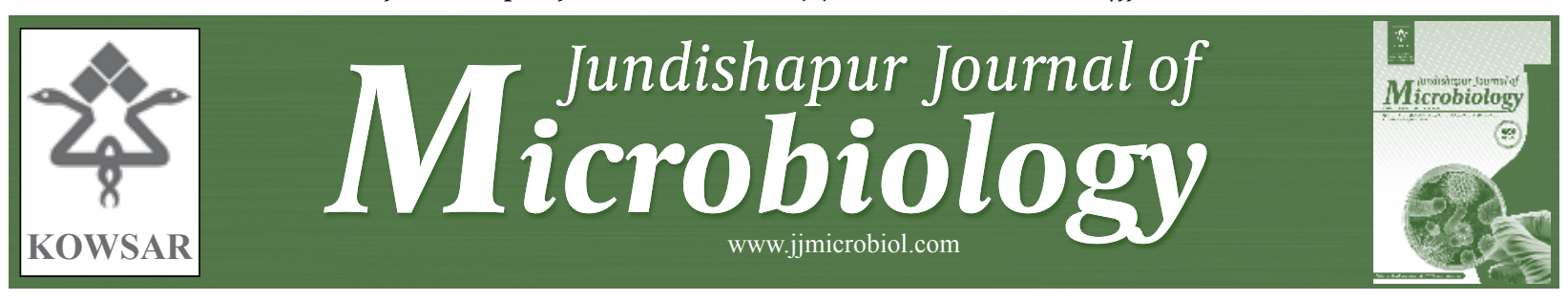

\title{
Assessment of Microbial Contamination and Physicochemical Condition of Public Swimming Pools in Kashan, Iran
}

\author{
Sima Rasti ${ }^{1}$, Mohammad Ali Assadi ${ }^{2}$, Leila Iranshahi ${ }^{3}$, Mahmood Saffari ${ }^{4}$, Hamid Reza Gi- \\ lasi $^{5,6}$, Mohammad Pourbabaee $^{7}$ \\ ${ }^{1}$ Department of Parasitology \& Mycology, Kashan University of Medical Sciences, Kashan, IR Iran \\ ${ }^{2}$ Department of Parasitology \& Mycology, Kashan University of Medical Sciences, Kashan, IR Iran \\ ${ }^{3}$ Department of Environmental Health, Kashan University of Medical Sciences, Kashan, IR Iran \\ ${ }^{4}$ Department of Microbiology and Laboratory Medicine, Kashan University of Medical Sciences, Kashan, IR Iran \\ ${ }^{5}$ Department of Epidemiology, Shahid Beheshti University of Medical Sciences,Tehran, IR Iran \\ ${ }^{6}$ Department of public Health, Kashan University of Medical Sciences, kashan, IR Iran \\ ${ }^{7}$ Department of Microbiology, Kashan University of Medical Sciences, Kashan, IR Iran
}

\section{A R T I C L E I N F O}

Article type:

Original Article

\section{Article history:}

Received: 02 Oct 2011

Revised: 09 Jan 2012

Accepted: 12 Jan 2012

\section{Keywords:}

Physicochemical

Parasites

Bacteria

Fungi

Contamination

Swimming Pools

\begin{abstract}
A B S T R A C T
Background: Swimming pools can transmit contagious diseases such as; fungal disease, otitis, conjunctivitis and amoebic meningoencephalitis.

objectives: The aim of this study was to determine the level of microbial contamination and the physicochemical condition of the swimming pools.

Materials and Methods: In this cross - sectional study, 200 water samples were collected from four swimming pools in Kashan, Iran. Temperature, $\mathrm{pH}$ and residual chlorine and turbidity of the pools were examined. Samples were concentrated through a membrane filter and sedimentation, to test for the presence of parasites, fungi, and bacteria.

Results: The results of the study showed that the mean of the physicochemical parameters, except in temperature, was standard in more than $60 \%$ of the pools. Average temperature was higher than standard. The highest chlorine level was recorded in summer. Coliform bacteria was found to be positive in $3 \%$ of the samples. Prevalence of saprophytic and opportunistic fungi was $27 \%$. Twelve species of fungi were isolated; the most common were Aspergillus, Penicillium sp, Rhizopus sp, and Fusarium sp, and the highest fungi pollution was observed in the summer. Prevalence of bacterial contamination was $9 \%$; bacteria isolate included Staphylococcus epidermidis, Bacillus subtilis and Escherichia coli. There was a significant association found between fungal and bacterial contamination with residual chlorine $(P=0.014,0.001)$.

Conclusions: The results showed that there were no parasites, or pseudomonas in Kashan's swimming pools, however, the prevalence of opportunistic saprophytic fungal contamination was relatively high. Such conditions may be attributed to a high temperature and insufficient water treatment. In addition, there is a need to monitor water quality and improve staff training to increase users' knowledge and awareness of the risks.
\end{abstract}

Copyright @ 2012 Kowsar Corp. All rights reserved.

- Implication for health policy/practice/research/medical education:

Most of the isolated fungi in the swimming pools can cause ear, eye and allergic diseases, therefore improvement the hygiene of swimming pools for control of microbial contaminations are recommended.

Please cite this paper as:

Rasti S, Assadi MA, Iranshahi L, Saffari M, Gilasi HR, Pourbabaee M. Assessment of Microbial Contamination and Physicochemical Condition of Public Swimming Pools in Kashan, Iran. Jundishapur J Microbiol. 2012: 5(3):450-5. DOI: 10.5812/jjm.2478

*Corresponding author: Mohammad Ali Assadi, Department of Parasitol-

ogy \& Mycology, Kashan University of Medical Sciences, Kashan, IR Iran.

Tel/Fax: +98-3615553648, E-mail: m_a_assadi@yahoo.com

DOI: $10.5812 / j j m .2478$

Copyright @2012 Kowsar Corp. All rights reserved. 


\section{Background}

The majority of people attend swimming facilities for; recreational activities, rehabilitative treatment or sport. In recent years, there have been many reported cases of infectious diseases caused by the inadvertent swallowing of swimming pool water that was contaminated with bacteria, fungi or protozoa cysts while swimming $(1,2)$. Giardia lamblia and Cryptosporidium and free living ameba have been reported in some swimming pools in the United States and Slovakia, respectively $(3,4)$. Most of the waterborne outbreaks of gastrointestinal disease, such as Salmonella sp. have been associated with recreational exposure (3). Approximately, $40 \%$ of the microorganisms isolated from swimming pools are $B a$ cillus which is due to the fact that they contain spores which are resistant to disinfecting substances, particularly percholorine(2). In the majority of cases Bacillus subtilisis considered to be a non-pathogen, but due to its dominant flora under some special circumstances it is thought to be the cause of; conjunctivitis, meningitis, pneumonia, and septicemia (5).

Pseudomonas are resistant to sodium hypocholoride that is used for disinfecting pools and it is considered to be an opportunist microorganism that is involved in urinary tract infections, wound in fections, sepsis and bed sores $(2,5)$. Despite the fact that these bacteria are not considered major threats and play no direct role in producing infections in humans, they should not be ignored when checking the water quality of swimming pools (2). Contamination of swimming pools has been reported in Gorgan and Shiraz, Iran with Pseudomonas aeruginosa and Ecoli $(6,7)$.

Approximately 10 to $20 \%$ of the general population worldwide is infected by dermatophytes. Dermatophytes are a type of fungus that can live on; external skin, within hair, and in skin lesions. They can be transmitted to others through direct contact such as swimming water, wrestling mats, and physical contact in sports (8). Pseudomonas aeruginosa, Staphylococcus aureus, Staphylococcus epidermidis, Penicillium sp, Rhizopus sp, Aspergillus, Fusarium sp, Trichophyton mentagrophytes and Mucor sp. were isolated from swimming pools in Nigeria (9). The most common fungi recovered in swimming pools in Uremia, Iran was Asepergillus spp. $56 \%$, and Candida spp. $22.9 \%$ (10). Other factors that may contribute to the spread of skin disease in the pools includes; water temperature, humidity, age, profession, life conditions, and ensuring the necessary hygiene to enter into the swimming pools (8). In addition to these factors, the physical and chemical conditions of the water such as; $\mathrm{pH}$ and residual chlorine levels within the pools are very important. Whenever the free chlorine level is below 0.04 $\mathrm{mg} / \mathrm{L}$ and the $\mathrm{pH}$ level measures 6.9 to 8.9 the activity of microorganisms within swimming pools increases, because by increasing the $\mathrm{pH}$, only a low percentage of residual chorine changes into hypochlorous (11).

Residual chlorine with a standard density of $1.5 \mathrm{mg} / \mathrm{l}$ or higher level is insufficient to eliminate any parasites and free living ameba within the swimming pools (4, $12,13)$. The presence of such infecting factors within the swimming pools can endanger swimmer's health and cause infectious diseases including; otitis, Candida vaginitis, trichomoniasis, oxyuriasis, keratitis or meningoencephalitis $(4,8,14,15)$.

The first step in providing a safe swimming environment is to provide healthy swimming pools, as well as a swimming environment free from fungi, parasites and bacteria. This type of policy protects the swimmers and prevents them from contracting communicable infectious diseases. Research has shown that nearly all swimming pools face the risk of culturing microorganisms which are harmful for human health.

\section{Objectives}

The purpose of this study was to determine the physicochemical, parasitic, fungal and bacterial contamination of public swimming pools in Kashan, Iran.

\section{Materials and Methods}

In this cross-sectional study, A total of 200 samples from the water of four indoor public swimming pools in Kashan, Iran (A- D; 33, 34,25,8 samples respectively) were taken in different seasons during 2008-2009. Standard procedure was followed for collecting samples using a manual plastic pump, in a $500 \mathrm{~mL}$ sterilized bottle (16). Samples were collected from the surface (100 samples) and $20 \mathrm{~cm}$ beneath the surface (100 samples) during 9-12 A.M. The residual chlorine, $\mathrm{pH}$ and temperature were examined on site and then the samples were transferred to the laboratory in a cool box and turbidity was measured. A thermometer was used to measure the temperature and turbidity was determined by (HACH Co, 2100 P turbidimeter; USA). The $\mathrm{pH}$ and residual chlorine was assessed by a DPD kit (N,N-Diethyl-p-Phenylenediamine kit) and phenol red $(16,17)$.

The standard of the physicochemical parameters of water in Iran are; turbidity less than 0.5 Nephelometric Turbidity Units (N.T.U) and residual chlorine 1-3 ppm, $\mathrm{pH}$ $7.2-8$, temperature $27-29^{\circ} \mathrm{C}(16)$. The physicochemical parameters were studied among 100 surface samples. For the purposes of diagnosing cysts or parasite eggs, fungi spores and bacteria, $150 \mathrm{~mL}$ of the samples were filtrated through Millipore filters with a pore size of $0.45 \mathrm{mi}$ crometers. Then, the filter paper was washed with $2 \mathrm{~mL}$ of sterile physiology serum and the residual water was centrifuged at $3000 \mathrm{rpm}$ for 8 minutes. Immediately after this process, the sediment was examined to see whether there were any trophozoites, protozoa cysts or worm eggs $(10,14)$.

Another $100 \mathrm{~mL}$ of the swimming pool water was 
passed through this filter. This filter was inoculated upside down over the Bactoagar medium enrichment with Ecoli. Following the closing of the plates with Para film, they were kept in an incubator at $30^{\circ} \mathrm{C}$ for one week (4). Then the plates were examined under the microscope to check for the presence of free living ameba colonies and the results were recorded in a check list. For the purpose of detecting fungal contamination, the sterile swaps were placed in the residual filtrated water; surface and deep samples, were then cultured in Saboroud -dextrose agar (S) and Saboroud -dextrose agar + chloramphenicol + cycloheximide (SCC). The plates were incubated at room temperature for two weeks and then the level of fungal growth was determined by routine laboratory methods. In cases where there were signs of colonial fungal growth it was designated positive, and then it was examined by the teased mount method or slide culture (8).

Bacterial examination was performed by testing the water sample sediment in nutrient agar medium and then it was cultured in Eosin Methylene Blue Agar (EMB) and blood agar, kept in an incubator at $37^{\circ} \mathrm{C}$ for 24 hours. In cases where the results turned positive, for the purpose of identification, Indol, Methyl red, VP, Citrate tests were used to count them (18). All of the mediums were from Merck, Darmstadt, Germany. These results were recorded on the recording forms, then the data were analyzed by using SPSS ver 16 and statistical tests including chi squared, Fisher's exact test, ANOVA and T test. This study was approved by the Ethics committee at the Kashan University of Medical Sciences.

\section{Results}

The findings indicated that the average; temperature, $\mathrm{pH}$, residual chlorine and turbidity of water in the swimming pools were: $30.6{ }^{\circ} \mathrm{C} \pm 1.9,7.7 \pm 0.29,1.5 \mathrm{ppm} \pm$ 0.7 , and $0.47 \pm 0.2 \mathrm{NTU}$ respectively. Frequency standard of the physicochemical parameters of swimming pools in Kashan, Iran is presented in Table 1. Temperature was standard in $10 \%$ of the swimming pools. Frequency distribution of residual chlorine according to the seasons in the public swimming pools is presented in Table 2.

The lowest level of residual chlorine was found during the winter (38.1\%), and the highest concentration was during the summer (94.4\%). Prevalence of fecal coliform was $3 \%$. (MPN = 9 fecal coliform per $100 \mathrm{~mL}$ ). No cysts, parasite eggs or free living ameba were found. On the other hand, various opportunistic saprophyte fungi were isolated from indoor swimming pools.The prevalence of fungal contaminations on the surface and at depth in the swimming pools were $42 \%$ and $12 \%$ respectively, and the overall prevalence was $27 \%$. In this research 12 types of opportunistic saprophyte fungi were detected. The most common fungal isolates included: Aspergillusspp. 50 \%, Rhizopus $13 \%$, Yeast $13 \%$, Penicillium spp $7.4 \%$ and Fusarium spp $3.7 \%$. No cases of dermatophytes were isolated. Fisher's exact test showed that there was no significant difference among the fungal contamination in all of the swimming pools $(P=0.97)$.

The highest rate of fungal contamination was observed during the summer (33.3\%) and the lowest rate was detected during the spring (18.5\%) (Figure 1). However, there was no significant difference among the seasonal rates of fungal contamination $(P=0.36)$.

Overall, 18 cases ( $9 \%$ ) of bacterial contamination were found. The highest and the lowest frequency were found during the fall and spring $17.6 \%$ (12 cases) and 1.8 $\%$ (1 case) respectively. The difference was significant $(P=$ $0.02)$. Prevalence of bacterial contamination in the water of the swimming pools was as follow: S. epidermidis $5.5 \%$, B. subtilis $2 \%$ and E. coli $1.5 \%$. Pseudomonas spp. were not isolated from the indoor swimming pools. There was a significant relationship between residual chlorine levels and bacterial contamination $(P=0.001)$.

\begin{tabular}{|c|c|c|c|c|}
\hline Swimming Pools & Residual chlorine, No. (\%) & Temperature, No. (\%) & pH, No. (\%) & Turbidity, No.( \%) \\
\hline A & $23(69.7)$ & $1(3)$ & $28(84.8)$ & $20(62.5)$ \\
\hline B & $21(61.8)$ & $5(14.7)$ & $32(94.1)$ & $22(64.7)$ \\
\hline $\mathrm{C}$ & $20(80)$ & $3(12)$ & $20(80)$ & $16(66.7)$ \\
\hline $\mathrm{D}$ & $7(87.7)$ & $1(12.5)$ & $8(100)$ & $5(62.5)$ \\
\hline Total & $71(71)$ & $10(10)$ & $88(88)$ & $63(63)$ \\
\hline
\end{tabular}

\begin{tabular}{llll}
\hline \multicolumn{4}{l}{ Table 2. Distribution of Residual Chlorine in Kashan's Swimming Pools according to the Seasons } \\
\hline & Standard, No. (\%) & Non-standard, No. $(\%)$ & Total, No. $(\%)$ \\
\hline Spring & $24(88.9)$ & $3(11.1)$ & $27(100)$ \\
Summer & $17(94.4)$ & $1(5.6)$ & $18(100)$ \\
Autumn & $22(64.7)$ & $12(35.3)$ & $34(100)$ \\
Winter & $8(38.1)$ & $13(61.9)$ & $21(100)$ \\
Total & $71(71)$ & $29(29)$ & $100(100)$ \\
\hline
\end{tabular}




\section{Discussion}

The results of this research showed that the mean of the physicochemical parameters except for temperature was standard at more than $60 \%$ (Table 1). The pH was standard in $88 \%$ of the swimming pools (Table 1).In comparison with the results from Gorgan, Iran, Kashan's swimming pools were in a better condition (6). In the present study a pH level greater than 8 (basic) was found in $8 \%$ of the samples, in basic $\mathrm{pH}$ conditions the disinfecting ability of chlorine is decreased (11). Data from this study suggests that the residual chlorine level of Kashan's swimming pools was $1.5 \mathrm{ppm}$ and was standard in $71 \%$ of the samples (Table 1). Mean residual chloride in swimming pools in Uremia and Shiraz, Iran were lower than the standard $(0.6 \mathrm{ppm})(7,10)$, so in comparison with these other studies, Kashan's swimming pools were in a better condition. A study conducted in Amman, Jordan, indicated that conformance of the pools water to the standards was 49.4 $\%$ for residual chlorine, $\mathrm{pH} 87.7 \%$ and water temperature $48.8 \%$ (19). Findings of the current study indicate that the residual chlorine of swimming pool water in Kashan, Iran was of a better quality in comparison with Amman, but the parameter of temperature was lower in Kashan, in comparison with Amman(19). No intestinal parasites and free living amebas were found in this study. Thus, the results were similar to those reported by Maida in Italy (20). The lack of parasitic contamination in Kashan's swimming pools may be attributed to the low rainfall and the use of deep underground water sources and low prevalence of intestinal parasitic diseases (21).

In the case of contamination of pools with free living ameba; Acanthamoebaand Naegleria, may lead to keratitis in the cornea or acute amebic meningoencephalitis that may lead to death $(4,14)$.

The majority of the swimming pools have a significant role in the spread of fungal diseases and ear problems (22). Factors such as; a pre-existing swimmer's skin infection as well as a failure to control $\mathrm{pH}$ levels and inappropriate disinfection measures are very important in the spread of disease $(8,15)$. It is a well known fact that there is a close association between chemical and physical properties; level of $\mathrm{pH}$ and free residual chlorine, temperature, swimmer's load and the degree of pollution in swimming pools. Through measuring the aforementioned factors, it is possible to predict the level of contamination in a swimming pool with a high degree of accuracy (17). Data from this study suggests that the prevalence of opportunistic saprophyte fungal contamination in the swimming pools was $27 \%$, which was lower in comparison with Isfahan, Iran (23). The results of this research also indicated that the $\mathrm{pH}$ of swimming pools in Kashan was close to the standard; such a condition is suitable for fungal growth and explains the reason behind the high degree of fungal contamination found in this study $(17,24)$.
Chlorine at the standard employed in swimming pools does not eliminate; fungi, parasites, and bacteria (16). However, $29 \%$ of the pools showed values below the standard which may be interpreted as a high prevalence of fungal contamination (Figure 1 and Figure 2). The results of this research showed that there was a significant difference between the residual chloride in the contaminated and non-contaminated swimming pools $(P=0.014)$. Such findings are in agreement with the results of research reported by Neghab; that when chloride drops to 0.7ppm, fungal contamination increases, while when this value exceeds 2.1, fungal contamination decreases (7). Maida claims that the quality of water depends on chloride con-

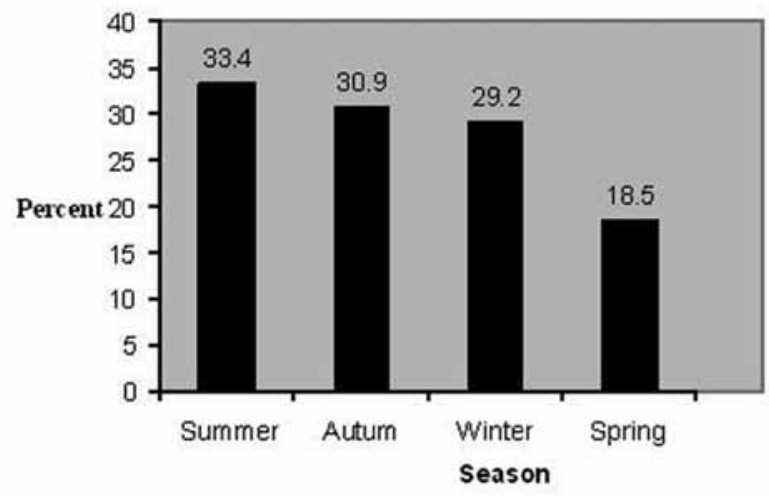

Figure 1. Distribution of Fungal Contamination of Swimming Pools According to the Seasons, in Kashan

centration and the number of swimmers attending the $\operatorname{pool}(20)$.

High temperatures prepare the conditions for disease causing factors. The ideal temperature for swimming pools varies between 27 to $29^{\circ} \mathrm{C}$. The results of this study showed that the temperature was not standard in $90 \%$ of the pools (Table 1) and in the majority of cases ( $88 \%$ ) they were higher than $29^{\circ} \mathrm{C}$, which is ideal for the growth of fungi and bacteria. In regard to the types of fungal contaminations isolated in the swimming pools, the highest frequency was observed for Aspergillus and the lowest for

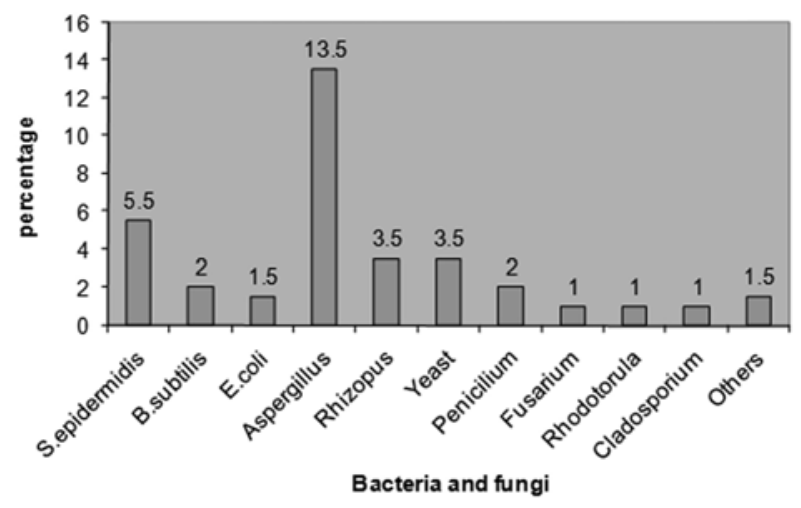

Figure 2. Distribution of Microbial Contamination of Swimming Pools According to the Types of Microbes, in Kashan 
Fuzarium, a condition similar to that which was reported in Italian, Nigerian and Iranian indoor swimming pools (10, 25-27). Considering the potential role of Fonychomycosis and Aspergillus as a starting point for disseminated infections in immune compromised patients, swimming pools constitute serious problems (28).

Dermatophytes have been reported in the swimming pools of Nigeria, while no such fungi were isolated in this study (9). In this research, the highest frequency of fungal contamination was found during the summer (Table.2), while the highest level of residual chlorine was also measured during this season, the result shows that chlorine has no influence on the decrease of fungal contamination and it would be better to replace it with other types of disinfectant. This is probably due to the high temperatures found during summer, in addition to the presence of humidity and fungal spores, thus making the conditions ideal for an increase in fungal growth. The results of this and other research indicates that one of the causes of microorganism contamination in swimming pools is an insufficient concentration of disinfectant (20).

In the present research S. epidermidis, B. subtilis and $E$. coli were isolated (Figure 2). A high prevalence of bacterial contamination was observed in the autumn and the winter, when the chlorine level was at its lowest level. These data are similar to other findings (20). S. epidermidis has been reported to cause hospital and opportunistic infections (29). Bacillus spp. form permanent spores and are resistant to disinfection, these bacteria are considered to be non-pathogenic, but have occasionally been isolated from cases of conjunctivitis, meningitis, pneumonia, and sepsis (5). In other research $P$. aeruginosa were reported $(2,10)$. Fortunately, in this research no case of these bacteria was identified. In research that was conducted by Maida and Gregori, P. seudomonas and S. epidermidis were also reported $(20,30)$.

Legionellosis agents from swimming pools and cooling towers have been reported in Khuzestan Province, Iran (31). Bacterial infectious diseases such as; E. coli, S. epidermis and P. aeruginosa may occur after swallowing swimming pool water $(1,2)$. Careful inspection of conditions such as; maintaining a standard temperature range, residual chloride levels as well as increasing the knowledge of the swimmers using the pools can decrease the likelihood of contamination as well as the transfer of infectious disease. Based on the results of this study, the rate of opportunistic saprophyte fungal contamination in the swimming pools of Kashan was relatively high, but bacterial contamination was relatively low, comparison with other studies. Such conditions may be due to the high temperatures and the low level density of chlorine which is ineffective in eliminating the fungi. Therefore, it is suggested that the standard level of residual chloride in these places be reexamined or replaced by stronger disinfectant substances. In addition, medical education programs for the individuals using these pools, as well as the personnel in charge of the pool facilities need to be offered.

\section{Acknowledgement}

The authors are grateful to the Vice chancellor in Research affairs of Kashan University of Medical Sciences for the financial support. We also thank managers of swimming pools Kashan, Iran for kindly cooperation.

\section{Financial Disclosure}

None declared.

\section{Funding/Support}

The study was finahcially supported by Grant no.8745.

\section{References}

1. Brewster DH, Brown MI, Robertson D, Houghton GL, Bimson J, Sharp IC. An outbreak of Escherichia coli O157 associated with a children's paddling pool. Epidemiol Infect. 1994;112(3):441-7.

2. Kiyohara N, Kobayakawa Y, Lyman H, Osafune T. Identification of bacterial flora in the water of swimming pools throughout the year. Japan J PhysEduc Hlth Sport Sci. 2006;51(1):1-9.

3. Dale K, Kirk M, Sinclair M, Hall R, Leder K. Reported waterborne outbreaks of gastrointestinal disease in Australia are predominantly associated with recreational exposure. Aust $N$ Z J Public Health. 2010;34(5):527-30.

4. Ondriska F, Mrva M, Lichvar M, Ziak P, Murgasova Z, Nohynkova E. First cases of Acanthamoeba keratitis in Slovakia. Ann Agric Environ Med. 2004;11(2):335-41.

5. Brooks GF, Butel JS, Carroll KC, Morse SA, Mietzner TA. Jawetz, Melnick, and Adelberg's medical microbiology. McGraw Hill Medical;2010.

6. Mehdi Nejad MH. The determination of quality of healthy indicators in swimming pools in Gorgan. J Gorgan Univ Med Sci. 2003;5(12):84-7.

7. Naghab M, Abolghasem Gorji H, Baghapour MA, Rajaeifard AR. A study of Shiraz pools contamination. Sci J Kordestan Univ Med Sci. 2000;31(8):41-9.

8. Rippon JW. Medical mycology: the pathogenic fungi and the pathogenic actinomycetes. Saunders; 1988.

9. Itah AY, Ekpombok MU. Pollution status of swimming pools in south-south zone of south-eastern Nigeria using microbiological and physicochemical indices. Southeast Asian J Trop Med Public Health. 2004;35(2):488-93.

10. Nanbakhsh H, Diba K, Hazarti K. Study of fungal contamination of indoor public swimming pools. Iran I Public Health. 2004;33(1):60-5.

11. Seyfried PL, Fraser DJ. Persistence of Pseudomonas aeruginosa in chlorinated swimming pools. Can J Microbiol. 1980;26(3):350-5.

12. Shields JM, Gleim ER, Beach MJ. Prevalence of Cryptosporidium spp. and Giardia intestinalis in swimming pools, Atlanta, Georgia. Emerg Infect Dis. 2008;14(6):948-50.

13. Sorvillo FJ, Fujioka K, Nahlen B, Tormey MP, Kebabjian R, Mascola L. Swimming-associated cryptosporidiosis. Am J Public Health. 1992;82(5):742-4.

14. John DT, Petri WA. Markell and Voge,s Medical parasitology. 9 th ed.; 2006

15. Zaenei F. Medical Mycology [In Persian]. 2 th Ed; 1997.

16. Institute of Standard and Industrial Research of IR. Swimming pool water Microbiological specifications. Tehran: Institute of Standard and Industrial Research of IR; 2007 [updated 2007]; Available from: http://www.isiri.org/Portal/Home/Default. aspx?CategoryID=b1361992-1938-41a8-b24e-d6ebb032a881.

17. American public Health Association. Standard Methods for the 
examination of water and waste water. 16 Th ed.: Washington DC, American Public Health Association Inc; 1974.

18. Mahon CR, Lehman DC, Manuselis G. Textbook of Diagnostic Microbiology. Elsevier - Health Sciences Division; 2010.

19. Rabi A, Khader Y, Alkafajei A, Abu Aqoulah A. Sanitary conditions of public swimming pools in Amman, Jordan. Int J Environ Res Public Health. 2008;5(3):152-7.

20. Maida CM, Di Benedetto MA, Firenze A, Calamusa G, Di Piazza F, Milici ME, et al. [Surveillance of the sanitary conditions of a public swimming pool in the city of Palermo (Italy)]. Ig Sanita Pubbl. 2008;64(5):581-93.

21. Arbabi M, Talari SA. Survey of intestinal parasites in students of Kashan University of Medical Sciences. J Ilam Univ Med Sci. 2004;12(44-45):84-7.

22. Wang MC, Liu CY, Shiao AS, Wang T. Ear problems in swimmers. Chin Med Assoc. 2005;68(8):347-52.

23. Shadzi SH, Pourmoghadas H, Chadeganipour M, Zare A. [Fungal contaminations in four swimming pools is Isfahan, Iran].JIUMS. 2001;1(12):28-31.

24. Salvato JA, Nemero NL, Agardy FJ. Environmental Engineering. 5th ed. Canada: John Wiely and Sons Inc; 2003.

25. Brandi G, Sisti M, Paparini A, Gianfranceschi G, Schiavano GF,
De Santi M, et al. Swimming pools and fungi: an environmental epidemiology survey in Italian indoor swimming facilities. Int $J$ Environ Health Res. 2007;17(3):197-206.

26. Mbata T, Ahonkhai I, Uzowuru R. Isolation of Fungi in Swimming pools in Enugu, Nigeria. Sudan J Dermatol. 2008;5(2):81-5.

27. Dindarloo K, Soleimani Ahmadi M, Zare SH, Abdi H, Heidari M. [Hygiene condition of Bandar Abbas swimming pools]. JHUMS. 2005;9(1):46-1.

28. Buot G, Toutous-Trellu L, Hennequin C. Swimming pool deck as environmental reservoir of Fusarium. Med Mycol. 2010;48(5):780-4.

29. Mironov A, Savitskaia KI, Vorob'ev AA. [Opportunistic microorganisms in urinary tract diseases]. Vestn Ross Akad Med Nauk. 2001(2):7-11.

30. Gregori NZ, Fechter HP, Miller D, Perez E, Diaz M. A Comparison of Bacteria Present in South Florida Ocean and Pool Water with Known Ocular Pathogens. Invest Ophthalmol Vis Sci. 2003;44(5):1428-

31. Moosavian M, Dashti A. Isolation and identification of legionellosis agents from fishponds, swimming pools and cooling towers in Khuzestan province, Iran. Jundishapur J Microbiol. 2011;4(4):209-15 